University of Nebraska - Lincoln

DigitalCommons@University of Nebraska - Lincoln

Faculty Publications: Department of Teaching, Department of Teaching, Learning and Teacher Learning and Teacher Education

Education

May 2007

\title{
Learning How to Make Inquiry into Electricity and Magnetism Discernible to Middle Level Teachers
}

\author{
Gayle A. Buck \\ Indiana University, gabuck@indiana.edu \\ Margaret A. Macintyre Latta \\ University of Nebraska-Lincoln, Margaret.Macintyre.Latta@ubc.ca \\ Diandra Leslie-Pelecky \\ University of Nebraska -- Lincoln, diandra2@unl.edu
}

Follow this and additional works at: https://digitalcommons.unl.edu/teachlearnfacpub

Part of the Teacher Education and Professional Development Commons

Buck, Gayle A.; Macintyre Latta, Margaret A.; and Leslie-Pelecky, Diandra, "Learning How to Make Inquiry into Electricity and Magnetism Discernible to Middle Level Teachers " (2007). Faculty Publications: Department of Teaching, Learning and Teacher Education. 25.

https://digitalcommons.unl.edu/teachlearnfacpub/25

This Article is brought to you for free and open access by the Department of Teaching, Learning and Teacher Education at DigitalCommons@University of Nebraska - Lincoln. It has been accepted for inclusion in Faculty Publications: Department of Teaching, Learning and Teacher Education by an authorized administrator of DigitalCommons@University of Nebraska - Lincoln. 
Published in Journal of Science Teacher Education (2007) 18:377-397. DOI: 10.1007/s10972007-9053-8 Copyright (C) 2007 Springer Science+Business Media, Inc. Used by permission. Journal of Science Teacher Education is the official journal of the Association for Science Teacher Education. Published online May 5, 2007.

The work reported within was partially supported by a National Science Foundation Grant. The opinions, views and conclusions expressed in this paper may not reflect those of the funding agency.

\title{
Learning How to Make Inquiry into Electricity and Magnetism Discernible to Middle Level Teachers
}

\author{
Gayle A. Buck \\ Department of Curriculum \& Instruction, Indiana University, W.W. Wright Education \\ Building, Bloomington, IN, USA. Corresponding author.Email: gabuck@indiana.edu
}

\section{Margaret A. Macintyre Latta}

Department of Teaching, Learning, \& Teacher Education, University of NebraskaLincoln, 118 Henzlik Hall, Lincoln, NE 68588-0355,USA.Email: mlatta2@unl.edu

\section{Diandra L. Leslie-Pelecky}

Department of Physics and Astronomy, University of Nebraska-Lincoln, 156 Behlen Laboratory, Lincoln, NE 68588-0111,USA.Email: diandra2@unl.edu

\begin{abstract}
As university professors we sought to disrupt the practice of giving our students the actions we felt they should imitate in their teaching practice. Instead, we sought to actively engage teachers in the creation of workable solutions to real-life problems. We accomplished this by conducting a participatory action research project. This paper illustrates our action research project focused on preparing middle level science teachers to foster inquiry-based learning in their classrooms. The findings of this study not only lead to a revised professional development opportunity for science teachers, but also provided an example of university faculty engaging in pragmatic research focused on addressing contemporary issues in K-12 science education.
\end{abstract}

\section{Introduction}

One of the goals of our nationally funded teachers/scientists program is to enhance middle level students' opportunities to learn science by increasing access to inquiry-driven experiences in content areas that satisfy national and state standards. Our initial attempts at fostering inquiry-based science instruction had positive effects; however, we felt inquiry practices should have a higher degree of impact than observed. We found the literature provided little guidance in regards to professional development in this area for middle level teachers; thus we conducted a participatory action research project: revising 
the professional development opportunity in light of our past experiences and literature on other areas of K-12 education, implementing the revised program, documenting the results of our efforts in regards to middle-level teacher inquiry practice, and making improvements/adjustments to our teacher development opportunity based on our results and teacher input. We focused our efforts on electricity and magnetism for three reasons: (a) the teachers requested that we align our efforts to an upcoming unit of study, and physical science was one of the areas in which they felt less sure; (b) prior experience with this unit provided a structure and experience on which to build; and (c) these concepts lend themselves easily to inquiry-based activities; however, there is a challenge in making the abstract concepts "real" to students.

\section{Background}

Inquiry-based science instruction continues to be a national focus in education. The national science standards (National Research Council, 2000) challenge science teachers to plan and guide inquiry-based science instruction for their students. These experiences must entail inquiry into authentic questions generated from student experiences, positioning learners to collaboratively attend to thinking processes, and building learning connections between self and subject matter. Recognizing teacher education's role in establishing such practices, the National Research Council also calls for quality professional development opportunities for teachers that involve ongoing reflection on the process and outcomes of understanding science through inquiry, as well as the use of inquiry and guided practice to build science understandings and science teaching skills.

The need to enhance the research base on professional development opportunities for inquiry-based instruction is well documented in the science education literature (e.g., Crawford, 2000; Keys \& Bryan, 2001; National Research Council, 1996). In light of this, there has been a growth of research on models for professional development opportunities focused on inquiry-based science instruction (e.g., Crawford, 2000; Hogan \& Berkowitz, 2000; Keys \& Kennedy, 1999; Supovitz \& Turner, 2000). However, the overall research base on inquiry-based instruction and professional development for such instruction is still lacking in several areas. Missing is an adequate portrayal of teacher beliefs about inquiry, the necessary knowledge base for teachers implementing inquiry, teacher inquiry practices, the quality of student learning from inquiry-based instruction, and studies focusing on middle and high school classrooms (Keys \& Bryan, 2001).

Science education reform efforts focused on inquiry-based instruction need a sound research base upon which to guide their efforts. Thus, it is critical for the science education community to enhance this base by researching inquiry-based instruction and professional development opportunities that, in some manner, address the areas of need.

\section{Guiding Literature}

Our teacher development opportunity was redesigned with the support of an extensive amount of literature. The focus of the literature was established in light of our goal to develop a middle level professional development experience that fosters inquiry-based classroom instruction during a unit on electricity and magnetism. The following is a review of those pieces that we found to be most influential in our efforts.

To further enhance understandings of developing and sustaining inquiry-based instruction in classrooms, Crawford (2000) and Keys (Keys \& Kennedy, 1999) studied the beliefs and practices of classroom teachers. Crawford (2000) studied a high-school biology teacher, while Keys (Keys \& Kennedy, 1999) studied an elementary teacher. In contrast to Crawford's (2000) study of a teacher already successfully implementing the inquiry approach, Keys (Keys \& Kennedy, 1999) focused on Kennedy: a teacher that was striving to develop an inquiry orientation. Both studies reported teaching characteristics that fostered inquirybased learning. These characteristics included: (a) situating instruction in authentic problems, (b) promoting the importance of student grappling with the data, (c) fostering collaboration between students and teachers, (d) connecting students with the local community, (e) modeling scientific behaviors, and (f) fostering ownership by students (Crawford, 2000). Keys and Kennedy (1999) added: (g) pausing instruction to investigate student questions, $(\mathrm{h})$ fostering independence associated with scientific work (challenging them to figure out the directions and carry out the experiments), (i) constructing explanations and concepts from data, and (j) applying scientific knowledge.

In order to foster this inquiry-based environment, the high school teacher in Crawford's (2000) study took on an expansive range of roles such as: (a) motivator, (b) diagnostician (successfully discerning student understanding), (c) guide, (d) innovator, (e) experimenter (testing new ways of teaching/assessing), (f) researcher (successfully evaluating and improving practice), (g) modeler, (h) mentor, (i) collaborator, and (j) learner. These roles of diagnostician, experimenter, and researcher are consistent with the roles emphasized by NorlanderCase, Campbell, Reagan, \& Case (1998). Keys' (Keys \& Kennedy, 1999) study of Kennedy also revealed challenges in implementing inquiry-based instruction. These challenges included (a) lack of time, (b) difficulty refraining from directly answering student questions, (c) teaching abstract curriculum objectives that did not lend themselves easily to inquiry-based instruction, and (d) district assessment instruments that focused on vocabulary.

Based on their findings, Crawford (2000) developed a model of inquirybased instruction, collaborative inquiry, which embraces the characteristics (af) and teacher roles described above. Keys (Keys \& Kennedy, 1999) emphasized the need for developmental research as a paradigm for teacher professional de- 
velopment: an approach that is in itself inquiry-based. This approach emphasizes the need to develop innovations with classroom teachers in the context of their own classrooms. This approach underscores the need for multiple cases of inquiry-based teaching at all grade levels, with a diversity of student populations, in a variety of communities.

Hogan and Berkowitz (2000) report on the outcomes of multiple teacher-development projects focused on inquiry-based instruction in ecology. The overall study focused on four different workshops that occurred across the country. Teachers and scientists collaboratively led the workshops, which focused on inquiry practices that focused on the schoolyard, and consisted of "an intensive two-week summer workshop, plus three formal follow-up sessions and ongoing informal support visitations during the school year" (p. 3). However, the four workshops were different in aspects that fostered an understanding of the variables that influence teacher professional development (e.g., urban/rural context) as well as on focus (e.g., teacher inquiry into student learning/developing guided inquiry activities for students). These researchers found that the teacher development programs all resulted in fewer concerns about teaching inquiry-based ecology, more teacher knowledge about ecology, and more examples of science being conducted in the schoolyard. However, they found a difference in the level of implementation of true inquiry-based practices. The differences in the findings reviewed in light of the difference in workshops led the researcher to conclude that it is important to (a) establish an open and supportive group culture that fosters risk-taking, (b) be flexible, yet hold clear standards, (c) establish and communicate a focus on changing oneself as a teacher or changing one's curriculum, and (d) recognize and foster the interdependence of content knowledge and inquiry processes. The final conclusion is supported by the research of Supovitz and Turner (2000), which also revealed the importance of fostering a positive attitude toward reform and deeper and more sustained professional development experiences.

Lunsford (2002) is a chemistry professor who developed and conducted a professional development workshop that focused on bringing inquiry-based learning to classrooms. The workshop included a 3-week summer institute that: immersed participants in learning physical science concepts through inquiry and had them develop one modular science activity to take back to their classrooms; guided development of a portfolio that included goal statements, table of contents, captions, reflections, and evidence; lead two one-day follow-up workshops in which the teachers reflected on their portfolios; and included one school visitation by the workshop leader. Lunsford's evaluation of her efforts indicate that the workshop led to increased content knowledge of the teachers and promoted the inquiry-based approach to teaching; however, the evaluation report from the experience provided limited understanding into the effects of the workshop due to the fact that major aspects of the evaluation were based on a pre- and post-questionnaire which included such agree/disagree questions as "students should not leave the science classroom confused or stuck" and "good science teachers show students the correct way to answer questions on which they will be tested," and one-time observations in which the participants selected one inquiry lesson to which to invite the facilitator. Overall, the experience lacked an adequate alignment between the in-service program and assessment: a critical component of professional development involving learning about and implementing scientific inquiry (Loucks-Horsley, Hewson, Love, \& Stiles, 1998; Luft, 1999). Luft's (1999) work centers on such alignment. She developed the Extended Inquiry Observational Rubric, which was utilized during a professional development opportunity on inquirybased science teaching. The rubric was utilized throughout the workshop and the findings provided a valuable means by which to progressively focus the workshop to better meet the specific goals of the workshop. Overall, this type of embedded assessment allowed for a "participant-centered, in-service program" (p. 10).

Based on this research, a professional development opportunity that successfully fosters inquiry-based practices in the classroom should be designed to prepare teachers to take on the necessary roles (e.g., diagnostician, experimenter), to situate their classroom instruction in authentic problems in a manner that promotes grappling with data, collaborating, modeling scientific behavior, student self-direction, and constructing explanations and concepts from experiences. The overall structure should foster inquiry-based learning in the context of the teachers' classrooms, extend over a substantial period of time, foster a supportive group culture, be flexible while having clear standards, increase content knowledge, and include an embedded assessment structure.

\section{Methodological Approach}

Our problem derived out of our social reality. Addressing this problem became the starting point for a participatory action research project. Participatory action research involves taking the construction and reconstruction of your own social reality into your own hands (Kemmis \& McTaggart, 2000). Participatory action research

frequently emerges in situations where people want to make changes thoughtfully - that is, after critical reflection ... when people want to think "realistically" about where they are now; how things came to be that way; and, from these starting points, how, in practice, things might change. (Kemmis \& McTaggart, 2000, p. 573)

Participatory action research generally involves a spiral of self-reflecting actions that include: planning a change, acting and observing the process and con- 
sequences, reflecting on the process and consequences, and then re-planning, acting and observing, reflecting, and so on... (p. 595).

We completed the "planning for change" by reviewing our current teacher development practice and the current literature on teacher development. We developed a general plan to revise our program, carried out the plan, and carefully observed the process and consequences. These findings were then analyzed and utilized to revise the teacher development program in a manner that would lead to a greater degree of impact on the classroom inquiry practices of middle level teachers. The results directly fed into the next iteration; thus, our inquiry does not end with a discussion of the program but a new teacher development opportunity-action.

\section{The Professional Development Opportunity}

Our general plan was a professional development opportunity for middle level teachers, called Making Scientific Inquiry Discernible. This professional development opportunity was a collaborative effort between education faculty, science faculty, and local middle-level science teachers. Making Scientific Inquiry Discernible focused on district objectives in sixth-grade electricity and magnetism. Overall, participants took part in a 3-month experience that included a one-day immersion into authentic inquiry on electricity and magnetism, half-day collaborative reflection on the immersion experience, half-day planning session, 3-month field experience with on-site collaboration with teacher educators and follow-up email correspondences, summative focus-group discussion/reflection, and individual interview.

\section{Participants' Roles}

Our inquiry team included two faculty members from the Department of Teaching, Learning and Teacher Education, one faculty member from the Department of Physics and Astronomy and six middle level science teachers. The similarities in the situations of the middle level teachers included: all taught at the sixth-grade level, all were employed by the same public school district, all followed the same district-defined curriculum, and all of their students completed the same district-wide science exams. The teachers were from five different school buildings within the district. The faculty members initiated the project and secured funding, which paid teacher stipends and included a modest equipment subsidy. The project was explained to potential participating teachers as a project in which the developers were seeking their experiences and input in order to revise an inquiry-based teacher development project. The teachers were aware of their participatory role in program development. The teachers received a stipend for all project hours outside of the existing school day (workshops, focus-group discussions, and individual interviews).

\section{Immersion Into Inquiry on Electricity and Magnetism}

Participants took part in a one-day workshop on the scientific concepts associated with the electricity and magnetism unit. This workshop was lead by three math and physics graduate students under the supervision of the science faculty team member. The graduate students were all participants in the project that initiated this activity and thus had prior experience working with both teachers and middle-school students on inquiry-based science activities. The education faculty team members took the role of participant-observers.

The activities were developed from questions collected from program participants prior to the workshop. The activities took part in a lab-like setting and focused on providing an immersion into authentic inquiry into electricity and magnetism for the participants. The process was designed to emphasize working cooperatively with the scientists, grappling with the data, and constructing the conceptual understanding needed to answer the central questions of the workshop. This was accomplished by starting with asking the teachers to list what they knew about electricity and magnetism and what they would like to know about electricity and magnetism. While the original intent of the question was to discern teachers' content knowledge, the teachers included a number of statements that emphasized their concerns about teaching these concepts. The scientist discussed safety concerns briefly, then participants were grouped into pairs and cycled through three stations that involved static electricity, magnets, and the connection between electricity and magnetism. Because the goal was for the teachers to experience genuine inquiry, some of the materials used and concepts addressed were extensions of their sixth-grade curriculum objectives.

Each station began with either the graduate student asking what the teachers wanted to know or with the teachers identifying a piece of equipment and asking the graduate student about it. Graduate students were monitored to ensure that they did not fall into "telling" mode. The scientist did a wrap-up activity where the initial list of "things we know" and "things we'd like to know" was reviewed and revised. Teachers also had some general questions ("Why are light bulbs different shapes?") that were addressed.

\section{Collaborative Reflection of the Immersion Experience}

The teachers and one of the education faculty members met for a one-half day reflective exploration of the immersion experience. In order to foster a supportive environment in which the teachers felt free to express their concerns and try new procedures, the participating faculty member, who is not associated with the large federally funded project within which the workshop was structured, facilitated the reflection and subsequent field experience. In addition, this facilitator was deliberately not involved in the "business" aspects of the work- 
shop (e.g., paying stipends and keeping attendance). The understandings established in this reflection were eventually enhanced/revised in light of practical application and collaborative feedback (described below). The reflection followed the immersion experience by one day. The close proximity of the followup session to the immersion experience allowed the participants to have a common foundation. The initial phase of the reflection focused on the experience, as well as the emotional and mental responses to the experience. The reflections, guided by the faculty member, ultimately uncovered the processes of grappling with the data, working cooperatively with the scientists, and constructing their own understandings. The teachers' responses to these experiences (e.g., vulnerability) were explored and the dynamic inquiry process evolved. This reflection served as a review of the experience of learning through inquiry and a preview of teaching using inquiry. Participants acknowledged holding a diluted understanding of inquiry-based instruction, which fostered questions about the difficult nature of inquiry and the commitment it takes to develop an inquiry-based classroom environment.

This developing understanding of the inquiry process was enhanced by the video, "A Case of Drawing to Learn," which vividly portrays a teachers' role in prompting inquiry via documenting an ongoing conversation focused on drawing a bicycle and explaining how it works. As the learner's drawing revealed what the learner did and did not know, the learner was assured that tentative, uncertain thinking was an important beginning. Increasingly the learner saw the drawing as a heuristic, a medium to learning. The drawing became a work in process; parts were reworked, crossed out, and reconsidered, as the learner talked about his drawing of the bicycle with the mentor, realizing gaps in thinking, locating terms, and seeing his drawing in a new way. The drawing served as "a platform for dialogue, a common referent for all to see, a theory that came from the child's own base of knowledge, a personal theory made visible and thinking more easily reconstructed" (Commentary Notes: A Case of Drawing to Learn). The drawing took shape as an initial theory, even at the risk of being wrong. And, so, the drawing made visible the student's inquiry as a conversation linking sense making. This conversation was skillfully guided by the mentor, generative, arising out of the subject matter and returning to the subject matter, reciprocal between learner, subject matter, and mentor, all enveloped in a conjoint, purposeful enterprise.

The collective reflections of the video were used to initiate a discussion on fostering student inquiry. The participants discussed how such a teaching process would look and feel (for the students and teacher) in general. They then discussed how such a process would look and feel in their sixth-grade science classrooms, ultimately focusing the discussion on the upcoming unit on electricity and magnetism.

\section{Planning Session}

The collaborative reflection was followed immediately by a planning session. Since all middle level teachers were going to teach the same unit, they were able to cooperatively discuss inquiry-based teaching strategies that could be utilized in their classrooms. The teachers self-organized into two collaborative groups, based on the length of their science class (40 or $80 \mathrm{~min}$ ), approximately halfway through the session. The project deliberately emphasized the value of practitioner knowledge of context and students, by placing the teachers in the facilitator role for this session; but the education faculty member remained for the discussions and initially raised some questions. The faculty member quickly took on the role of providing copies and supplies while the teachers planned. This session closed with the teachers sharing plans and with an understanding that each teacher was to become a teacher/researcher seeking to generate inquiry, as they taught this unit in their own classrooms.

\section{Field Investigation and Continuing Collaborative Reflection}

The teachers conducted their field investigations throughout a 3-month period (which included a Holiday break). They were asked to keep a portfolio that included all planning documents, reflections, student work, and their responses to students as part of their investigation. The education faculty member that facilitated the collaborative reflection of the immersion into inquiry visited each classroom once a week. While in the classroom, this faculty member actively worked with students and contributed to class discussions in a manner that would foster student inquiry. Following each visit, she emailed her reflections of the experience and reflection questions to the teacher. The teachers were asked to e-mail back their own reflections; they did not have to address the faculty member's questions specifically. A sample reflection statement is:

The personal accounts of magnets (can opener, magnetic paint) drew students into the learning experience. And you very artfully connected your request to sketch the can opener at home to everyone drawing and diagramming throughout the unit of study on electricity and magnetism... They were very serious, but unsure of why they were drawing.

A sample question posed to the teachers is: "Have you noticed any students frustrated with being asked to be inquirers? If so, how do you respond to them?" 


\section{Focus Group Discussion/Reflections}

At the completion of the field experience, participants came together for a focus group discussion/reflection. This took part at one of the teacher's school site and lasted approximately $90 \mathrm{~min}$. All members took part in the focus group and discussed topics including: (a) successful inquiry projects and why they were successful, (b) unsuccessful inquiry projects and why they were not successful, and (c) evidence of students becoming inquirers. The group also collaboratively reflected on the overall structure of the professional development opportunity and ways in which it should/should not be adjusted for other teachers in the district.

\section{Observing the Process and Consequences}

Guiding Questions. Our observation of the processes and consequences of our teacher development opportunity was guided by four questions. These included:

1. What teacher inquiry practices occurred throughout the unit on electricity and magnetism? How did the teachers' interpretations of inquiry-based instruction affect the inquiry practices?

2. What were the instructional challenges the teachers faced? Did they attempt to overcome them? If so, how?

3. What types of student documents resulted from the inquiry-based instruction? What did those documents reveal about student learning?

4. What aspects of the professional development opportunity did the teachers value the most and what aspects of the opportunity would they change?

Data Collection. Field Notes from Workshops. Content outlines for the teacher development activities. During the activities, facilitators made notes on what was/was not working, teacher responses, and interpretations of teacher responses. After the professional development activities, any reflections the facilitators felt were relevant were added to the field notes.

Field Notes from Classrooms. Each classroom was visited once a week during the field experience. The faculty visitor recorded the experience and observations in the form of field notes. The notes documented the activities of the students, teachers, and facilitator, as well as the facilitator's notes in regards to the guiding questions - these questions were often utilized in the subsequent email correspondences.

Email Correspondence. Following classroom visits each classroom teacher received reflections and follow-up questions. They responded with their own questions and reflections. These e-mail correspondences were printed.
Focus-group Discussion. All participants took part in a focus group discussion/ reflection at the conclusion of the field experiences. This discussion was audio taped and transcribed verbatim.

Individual Interviews. Each teacher participated in a one-on-one interview at the completion of the program. The interviews took place at the teacher's school site and lasted approximately $30 \mathrm{~min}$. Sample interview questions included: (a) What does inquiry mean to you? (b) How does inquiry affect planning? (c) What resources did you draw upon? and (d) What ways were you able to see into student thinking or inquiry processes?

Portfolios. All teachers were given a file box at the beginning of the project. This box contained sections for student work and responses to students. In addition, all teachers were asked to submit any classroom worksheets, their planning notes and reflective comments. All data were copied and the originals were returned to the teacher.

\section{Findings}

\section{What Teacher Inquiry Practices Occurred Throughout the Unit on Electricity and Magnetism? How Did Their Interpretations of Inquiry- based Instruction Affect the Inquiry Practices?}

The analysis of the verbatim interview transcripts (focus-group and individual), field notes, and planning documents revealed that all participating teachers held similar understandings of the inquiry process; their definitions illustrated an understanding of "questioning," "genuine learning," "a process of learning" which "takes you to the next level and figuring out how to ... how am I going to dive deeper into this?" However, their understandings of the role of inquiry in their classroom (inquiry-based instruction) differed. Although they all understood inquiry-based instruction in terms similar to what one teacher stated as "letting go" (a term used often throughout the process), their understanding of what they were letting go of differed. Some teachers emphasized the physical aspects of the inquiry process. In reflecting on their successes in implementing inquiry-based teaching, these teachers mostly would comment on their (in)ability to let go of a classroom management style that included keeping students in their seats and listening to the teacher. These teachers made comments such as, "I'm the kind of teacher that hates to give up control [in regards to behavior]. ... I've seen that it can and does work." Or, "I was petrified, I thought it was going to be utter chaos and those were the days they were best behaved and I was amazed." For these teachers, success was allowing the students to be physically active. In contrast, other teachers put the emphasis on the mental aspects of the process. For example, when asked if she had been concerned about letting go in the physical sense of classroom management, one teacher com- 
mented, "No, I was okay. What I hesitated about ... my hidden agendas ... what I want them to get." In reflecting on successes of implementing inquiry-based instruction, teachers, such as the one described, more often commented on their (in)ability to let the students guide their own thinking process. These teachers made such comments that described inquiry-based instruction as "... helping the students question what it is they're learning without me telling them. And helping them find ways to answer their own questions...," and " ... kind of helping decide which direction to go ...." One described a mental process when she stated, "During the process, I discovered more questions students raised, their inquiry discoveries became more evident and after it was kind of an evolution ... I discovered ... that I can discover science with the kids." These differences, emphasizing a physical or mental process, resulted in diverse inquiry practices throughout the unit on electricity and magnetism.

One example of a "successful" inquiry lesson for a teacher emphasizing inquiry in the classroom in regards to physical activity was a lesson on magnetic fields. The teacher had the students stand up and physically move to demonstrate magnetic fields, “... they're standing and doing the motions of aligning themselves ... we tried to be active even if they weren't touching magnets all the time." In contrast, an example of a "successful" inquiry lesson for a teacher emphasized inquiry as enabling students to realize their thinking through the construction of a working model building a compass. At the conclusion of the construction, it was discovered that not all of the needles pointed North. The teacher spontaneously encouraged the questions about this phenomenon, as well as about the process they should take to answer these questions. Ultimately, questions arose about controls, especially in regards to the environment in which the compasses were tested. The students were encouraged and guided as they questioned and explored why a standard hands-on activity did not produce the expected results.

\section{What Were the Instructional Challenges That the Teachers Faced? Did They Attempt to Overcome Them? If So, How?}

The analysis of the verbatim interview transcripts (focus-group and individual), field notes from classrooms, e-mail correspondences, planning documents, and portfolios revealed that although classroom management was a critical component in the teachers' ability to authorize inquiry, it was not an instructional challenge that emerged during the process. The instructional challenges that did emerge from the data involved the teachers' ability to assess students' knowledge construction during the inquiry process, as well as their own background knowledge of the content.

At the completion of the professional development experience, most of the teachers expressed a lingering frustration with their inability to assess their students' emerging understandings. As one teacher noted, “... I just felt like we spent so much time, and we really worked hard to make sure it was hands-on and totally inquiry and then at the very end, it was like, 'Okay, now here is the test?" Another noted, "I think after doing the inquiry with the kids, I felt frustrated because I had no clue how to assess it ... okay we did that, what do I do with it. ... I mean, I know they learned something, but how do I?" The portfolios supported the fact that this was an instructional challenge. The student work featured in these portfolios revealed very little about the knowledge construction of students. For example, many of the assessment artifacts were multiple choice quizzes or reproductions of teacher illustrations. This is further illustrated in the next section.

In the collaborative reflections on this challenge, most teachers revealed an uncertainty of how to overcome this problem (beyond looking to the facilitators for answers). Only one teacher ventured to attempt a solution as she reasoned in the collaborative focus group, "I think next time, I'd toss it up. I would ... sort of put it into words, not just pictures, not just diagrams, but to use the words along the way, so that when they got to [standardized test] it's like okay. But also, I think I'd like to create, and I didn't, but my own assessment at the very end, you know, like set up two magnets that are repelling, create a circuit ... instead of "here's a test, good luck reading."

As noted above, the teachers faced situations in which their own content knowledge became an instructional challenge in the classroom. As one teacher noted,

I am definitely much, much more comfortable setting out and doing inquiry with what I have stronger content knowledge. ... If I don't know enough to know if they are going to go off in a wrong direction, then I think that this whole idea of inquiry really could be pointless ... I would rather... let them go and then guide them in places that they weren't sure, and ask the key questions that would help them go in the right direction.

The teachers confessed that they got overwhelmed when the inquiry process led to an increasing number of content-related questions.

And then they even had more questions, so it just fed off of each other ... you had the experiment, you asked some more questions, you had the content and then you asked some more questions. And where does that lead to? And we had several students who just all of a sudden were just, "Oh, what about this?" or we'd be in the middle of an experiment, "What if you did this with that" ... the inquiry was just sort of bubbling ....

The teachers were more apt to attempt to overcome content challenges than assessment challenges. In the focus group discussion and collaborative reflection, the teachers discussed how they addressed this content challenge. One 
teacher noted she "used scientists" and did "a lot of "Ask Jeeves"”. ... Another stated that

we did a lot of "where we could find this on the internet" and we figured out, well, where could we go to find out how things worked ... I did it, and then I'd go back and say... "Here's the answer to yesterday's question."

Another teacher noted that she would say, "Boy that's a great question, let's write that down ... so we can ask [a scientist] or let's look it up."

\section{What Types of Student Documents Resulted From the Inquiry-based Instruction? What Did Those Documents Reveal About Student Learning?}

The analysis of field notes from classrooms and portfolios revealed that the instructional challenge of assessment also revealed itself in the student documents that resulted from this professional development opportunity. The collection of student documents did not allow for an adequate understanding of student learning: an understanding of critical importance in facilitating student inquiry. Of the extensive amount of student work generated during the program, an overwhelming majority allowed for little/no understanding of student learning. For example, the student-work portfolio of one teacher contained $101 \mathrm{stu}-$ dent-generated documents. Of these, $27 \%$ were coded as documents that provided no understanding of student learning, 49\% were coded as documents that provided little understanding, $25 \%$ were coded as documents that revealed a limited understanding of students' knowledge construction, and none of the documents provided a thorough understanding of student learning. The percentages for other teachers reflected similar percentages of the latter two categories, even if the percentage of documents were significantly different for the first two categories. For example, the student portfolios collection of another teacher contained 378 student documents. Of these, 70\% were coded as documents that provided no understanding of student learning, 3\% were coded as documents that provided little understanding, 25\% were coded as documents that revealed a limited understanding of students' knowledge construction, and $2 \%$ of the documents provided a thorough understanding of student learning. Unfortunately, it is the documents from the last two categories that are necessary in order to foster inquiry learning.

A large number of the documents in the first two categories were mainly the result of the teachers' attempts to foster learning in the classroom. The teachers augmented classroom activities with notes in attempts to foster the learning of vocabulary and solidify conceptual understandings. These documents consisted of copies of activities completed in class, class notes, vocabulary lists, and pictures originally drawn by the teachers. Also included were fill-in-the- blank worksheets, matching vocabulary sheets, and lab sheets that involved basic repetition of the physical activity. Any deviations by individual students on the above documents demonstrated a student's inability to copy, describe (not explain) a physical activity, or recall basic facts/definitions. As noted, many of these documents were not intended to reveal information on student learning; thus, their existence was not an indication of an area of concern. However, the lack of documents that allowed for an understanding of student learning did manifest itself as an area of concern.

Teachers were consistent in that they required that the students produce a very limited number of documents that would provide them with an understanding of student learning during, or as a result of, the inquiry process. The documents that did reveal information were the ones that sought student "thinking." For example, one teacher began each new topic by having the students complete a version of the KWL process. Students were asked to note everything they knew about a subject, as well as what they had questions about. Student questions such as: "How do they make a magnet?" "Where do magnets come from?" allowed for a limited insight into what they knew/didn't know, and what they thought about when a certain topic was mentioned. Another example of documents that revealed something about student learning were notebook pages in which the students wrote what happened in an experiment, what they learned, and how they learned it. For example, lab sheets from one class period required the students to describe what happened during several experiments on static electricity. The students were then asked to explain what the experiment revealed to them and how it was revealed - one student wrote: "friction [was produced]" he knew that because "the salt was attracted to the balloon" and "salt jumped." Insight about student learning also occurred when the students were (a) allowed to write any "stories" about a subject (e.g., "Coming back from Colorado my dad and I saw a Oldsmobile explode at the gas station because of static electricity."), (b) asked to write their initial thoughts about a question, and (c) asked to summarize what they learned (e.g., "[we learned] about how different things attract or repel, and a Latin American word and how make scientific contraptions"). The student responses from the above documents provided valuable information that would allow a teacher to guide student learning. The difference between documents that provided an adequate understanding and a thorough understanding were the amount of information that students provided in response to the teachers' prompts. The same assignment could result in one student revealing everything she/he knew, while another student would simply write one or two words. One teacher appeared to understand that and skillfully worked to encourage the students to reveal their thinking. This teacher often commented on the students' writings, comments that encouraged the students to explain further. For example, the teacher would ask the students to "Use words to explain how you think a light bulb works when you plug a lamp into an elec- 
trical outlet" or "Why do you think the can was moving?" and "Did this relate to any of our activities with magnets? Explain why or why not." Like in the other classrooms, in the beginning some students would write many thoughts and others would write a word or two. However, unlike most of the documents retrieved from other classrooms, these documents had many responses from the teacher. These would range in scope from "Great" to "How is the magnet that you bought like the magnets in school? How is it different?" (in response to a student's story) and "Why not? Are some magnets stronger than others? Tell me what you think!" Often, these students would respond back. But, the most beneficial outcome of the amount of teacher response was a much higher quality of student responses by the later stages of the document collection. Overall, the documents collected from this teacher's class revealed the most information about student learning - even though this teacher required many of the same assignments.

\section{What Aspects of the Professional Development Opportunity Did the Teachers Value the Most and What Aspects of the Opportunity Would They Change?}

The analysis of the verbatim transcripts (focus-group discussions and individual interviews) and field notes from workshops revealed that all of the participating teachers valued the professional development opportunity, Making Scientific Inquiry Discernible. Many expressed statements such as, "I enjoyed it," "I thought it was an incredible opportunity," "I would say what we gained from this project was a lifesaver for me," and "I feel very lucky that I was able to be associated with it." One participant noted that, "I think most people would be willing, you know, to have another one." This was ultimately supported by the fact that all of the teacher participants independently asked to be involved in any future opportunity that will be developed as a result of this experience.

The aspects of the opportunity they valued most included the content preparation, interactions with colleagues, and professional feedback. In the interviews, the teachers often commented on these components. Sample comments on the content preparation included,

I basically felt like I had very little knowledge walking in, and so that day that we spent on content ... as we were going ... I'd click back ... it was the experience I could fall back on, prior knowledge.

Sample comments on the interactions included, "...talking to colleagues, that day we planned, I mean ... we all did our little inquiry together." "We got to bounce ideas and I see what she's doing...." Sample comments on the feedback from the workshop facilitator included,
I appreciated having you come out and just the dialogue or email with you. It was reaffirming to have another adult because ... just to help me out [or] ... you're doing fine, or maybe you could ask this, or what did you think here?

And, “...immediate [feedback], thanks for sending that every time. It was so fast, right back to you ... because it was fresh in my mind...."

The teachers' suggestions for improvement involved enhancing the previously described components. Specifically, they suggested that we "...split content unit and cover one [at a time]" and "...come up with a list of [content experts] to contact." They also requested that we "Get together more." Perhaps, "get together midway to share what's been working," "work all in teams," "visit each other," or "maybe if we had checked in ...maybe just through email ... maybe just a little more communication" for "more feedback from each other." In addition to these enhancements, they also requested that a component on assessment be added. They made such statements as, "I would have liked more on assessment." "In retrospect, I wish I had done more authentic assessment."

\section{Reflections and Revised General Plan}

These findings indicate that this type of professional development opportunity does increase the teachers' attempts to increase inquiry-driven experiences; however, the findings also reveal several areas in which we can improve the program in order to assure that those attempts are successful. Our revised professional development opportunity, including the adjustments described below, also will be carefully monitored to further inform our efforts to make inquiry on electricity and magnetism discernible to middle-level teachers.

\section{Content Aspects}

The findings revealed a need to enhance our efforts to assure the teachers have the content knowledge necessary to facilitate inquiry-based learning. Content knowledge and the inquiry process are interdependent (Cohen \& Hill, 1998; Hogan \& Berkowitz, 2000; Supovitz \& Turner, 2000): What the inquirer already knows about a topic greatly influences the strength of the investigation. Like Hogan and Berkowitz (2000), we found that it is important for the teachers to be willing to ask questions right along side the students; but that there is a basic amount of content expertise necessary to be able to guide and facilitate student inquiry. Our exploration revealed the need to develop that expertise beyond what our process offered.

In light of this, we are revising our program to include more support in this area. In addition to the initial immersion into the content area, we will establish an on-line "Ask a Scientist" section where teachers can submit the content 
questions that arise throughout the inquiry process. Graduate student scientists will answer the questions the teachers post. The answers and questions will be posted on the web so that a "knowledge base" can be established and referred to by all teachers.

The need for a content component at mid-term was also indicated by the findings. Students raised many questions and those raised further questions in the teachers' minds. Having a half-day, sit-down experience where teachers can do similar sharing and reflecting, with an emphasis on the content aspects of the unit and content experts on hand, will provide further information about how effective this mode of support is, as well as helping us understand how science faculty can be effective participants in teacher professional development.

\section{Assessment}

Like content knowledge, assessment is also a critical component in the inquiry process. Our findings indicate that, if the teachers are to take on the roles emphasized by Crawford (2000) (e.g., diagnostician and guide), they will need to further enhance their abilities to assess student learning. Assessment can no longer be viewed as only a means to rank students or measure outcomes; assessment must be understood as a critical component in helping students learn and in improving instruction (Shepard, 2001). Our investigation revealed that assessment was not used or understood in this manner. Thus, our process must be adjusted to acknowledge the importance and enhance the use of assessment in the inquiry process. To accomplish this, formative assessment strategies will be introduced during the immersion experience. The science activities in which the teachers participated will involve an immersion into formative assessment; the teachers will be asked to complete such assessment as they participate in the activities. These completed assessments will be reviewed during the reflection period as the teachers are asked to discuss what the various artifacts reveal about their thinking during the activities. Following this, the teachers will review student assessment artifacts from the initial program. The teachers will be asked to analyze the artifacts in a similar manner to what was completed for this study. During the mid-term meetings, teachers will then analyze assessment artifacts from their own classrooms, reflect on the understandings revealed, and use those understandings to guide their plans.

\section{Teacher Input}

The participants of this project greatly valued the collaborative relationship established in this pragmatic research study. The working relationships fostered between the teachers, as well as between the researchers and teachers, had a positive effect on the efforts. The approach we followed to explore avenues to improve our teacher development program proved to be one of the most critical components to the teacher development process - we worked with the teachers. Overall, universities such as ours are devoted to knowledge creation and critical reflection. Yet, too often we frustrate learning by emphasizing the imitation of the professor's thoughts rather than active engagement in a joint inquiry process (Levin \& Greenwood, 2002). Approaches grounded in pragmatic philosophical traditions offer a better approach to education in the university community. In pragmatic research, the learning process occurs through a cycle of reflection and action in relation to the social reality of the participants. This approach is both central to the scientific method and to the democratic process (Levin \& Greenwood, 2002). Greenwood and Levin (1998) equate democracy "with the creation of arenas for lively debate and for decision making that respects and enhances the diversity of groups" (p. 11). The process of working with the teachers to monitor and adjust practice will continue. Our revised program will continue to include a strong emphasis of collaboration between teachers and teachers and researchers. As described above, there have been several meetings added to our process. These meetings will continue to be viewed as collaboration/focus group meetings in which we share expertise and work together. The focus will remain on improving practice - theirs and ours.

\section{Conclusion}

This study provided an opportunity for university faculty to work together with K-12 teachers to see and articulate the opportunities needed to establish a practice that fosters student inquiry into scientific topics. Together, we addressed the need to enhance the research base for inquiry-based instruction (see Crawford, 2000; Keys \& Bryan, 2001; National Research Council, 1990) by addressing four of the areas of need expressed by Keys and Bryan (2001): adequate portrayal of teacher beliefs about inquiry, the necessary knowledge base for teachers implementing inquiry, teacher inquiry practices and studies focused on middle school classrooms. Our initial attempts were developed with the support of an extensive amount of literature (see Guiding Literature). A1though these attempts fostered positive results in the classrooms, we continue to seek a higher degree of positive impact. Our participatory action research approach provides further understandings that enhance the literature base. Specifically, our work allows for a more complete understanding of the type of content support teachers need, as well as the type of assessment knowledge/skills needed by the teachers. In addition, the overall experience provides further evidence of the value of university faculty collaboratively engaging with teachers in pragmatic research focused on addressing contemporary real-world problems. As recently noted by Clift and Brady (2005) science teacher education is "beginning to move toward a conceptual, inquiry-based view of science teaching" (p. 320) but "moving to action is more difficult than the intention to do so" 
(p. 322). Indeed, these are key to our findings and affirm the necessity of developing and sustaining professional development initiatives that conjointly confront and examine the concrete particulars of science learning within the classrooms. And so, we press on, beginning our next adventure into making inquiry into science more discernible for middle level teachers.

\section{References}

A case of drawing to learn. Performanetics Video Production. Amherst, MA.

Clift, R., \& Brady, P. (2005). Research on methods courses and field experiences. In M. Cochran-Smith \& Zeichner K. (Eds.), Studying teacher education (pp. 309 424). Mahwah, New Jersey: Lawrence Erlbaum.

Cohen, D., \& Hill, C. (1998). State policy and classroom performance: Mathematics reform in California. CPRE Policy Briefs, RB, 23, 1-10.

Crawford, B. (2000). Embracing the essence of inquiry: New roles for science teachers. Journal of Research in Science Teaching, 37(9), 916-937.

Greenwood, D., \& Levin, M. (1998). Introduction to action research. Thousand Oaks, CA: Sage.

Hogan, K., \& Berkowitz, A. (2000). Teachers as inquiry learners. Journal of Science Teacher Education, 11(1), 1-25.

Keys, C., \& Bryan, L. (2001). Co-constructing inquiry-based science with teachers: Essential research for lasting reform. Journal of Research in Science Teaching, 38(6), 631-645.

Keys, C., \& Kennedy, V. (1999). Understanding inquiry science teaching in context: A case study of an elementary teacher. Journal of Science Teacher Education, 10(4), 315-333.

Kemmis, S., \& McTaggart, R. (2000). Participatory action research. In N. Denzin \& Y. Lincoln (Eds.), Handbook of qualitative research. Thousand Oaks, CA: Sage.

Levin, M., \& Greenwood, D. (2002). Pragmatic action research and the struggle to transform universities into learning communities. In P. Reason \& H. Bradbury (Eds.), Handbook of action research. Thousand Oaks, CA: Sage.

Loucks-Horsley, S., Hewson, P., Love, P., \& Stiles, K. (1998). Designing professional development for teachers of science and mathematics. Thousands Oaks, CA: Sage.

Luft, J. (1999). Assessing science teachers as they implement inquiry lessons: The Extended Inquiry Observational Rubric. Science Education, 8(1), 9-18.

Lunsford, S. (2002). In-service inquiry. The Science Teacher, 69(2), 54-56.

National Research Council. (1996). National Science Education Standards. Washington, DC: National Academy Press.

National Research Council. (2000). Inquiry and the National Science Education Standards. A guide for teaching and learning. Washington, DC: National Academy Press.
Norlander-Case, K., Campbell, P., Reagan, T., \& Case, C. (1998). The role of collaborative inquiry and reflective practice in teacher preparation. The Professional Educator, 21(1), 1-14.

Shepard, L. (2001). The role of classroom assessment in teaching, learning. In V. Richardson (Ed.), Handbook of research on teaching. Washington, DC: American Educational Research Association.

Supovitz, J., \& Turner, H. (2000). The effects of professional development on science teaching practices and classroom culture. Journal of Research in Science Teaching, 37(9), 963-980. 